\title{
Envisioning the Future of European Food Systems: Approaches and Research Priorities After COVID-19
}

\section{OPEN ACCESS}

Edited by:

Andrea Pieroni,

University of Gastronomic

Sciences, Italy

Reviewed by:

Renata Sõukand,

Ca' Foscari University of Venice, Italy

Cornelia Butler Flora,

lowa State University, United States

*Correspondence:

Fabio De Menna

fabio.demenna2@unibo.it

Specialty section:

This article was submitted to Social Movements, Institutions and

Governance,

a section of the journal Frontiers in Sustainable Food Systems

Received: 16 December 2020 Accepted: 12 February 2021

Published: 09 March 2021

Citation:

Vittuari M, Bazzocchi G, Blasioli S, Cirone F, Maggio A, Orsini F, Penca J,

Petruzzelli M, Specht K, Amghar S,

Atanasov A-M, Bastia T, Bertocchi I,

Coudard A, Crepaldi A, Curtis A,

Fox-Kämper R, Gheorghica $A E$,

Lelièvre A, Muñoz P, Nolde E,

Pascual-Fernández J, Pennisi G,

Pölling $B$, Reynaud-Desmet $L$,

Righini I, Rouphael Y, Saint-Ges V,

Samoggia A, Shaystej S, da Silva M,

Toboso Chavero S, Tonini P,

Trušnovec G, Vidmar BL, Villalba $G$

and De Menna F (2021) Envisioning

the Future of European Food

Systems: Approaches and Research

Priorities After COVID-19.

Front. Sustain. Food Syst. 5:642787.

doi: 10.3389/fsufs.2021.642787
Matteo Vittuari ${ }^{1}$, Giovanni Bazzocchi ${ }^{1}$, Sonia Blasioli ${ }^{1}$, Francesco Cirone ${ }^{1}$, Albino Maggio ${ }^{2}$, Francesco Orsini ${ }^{1}$, Jerneja Penca ${ }^{3}$, Mara Petruzzelli ${ }^{1}$, Kathrin Specht ${ }^{4}$, Samir Amghar ${ }^{5}$, Aleksandar-Mihail Atanasov ${ }^{6}$, Teresa Bastia ${ }^{7}$, Inti Bertocchi ${ }^{8}$, Antoine Coudard ${ }^{9}$, Andrea Crepaldi ${ }^{10}$, Adam Curtis ${ }^{11}$, Runrid Fox-Kämper ${ }^{4}$, Anca Elena Gheorghica ${ }^{12}$, Agnès Lelièvre ${ }^{13}$, Pere Muñoz ${ }^{14}$, Erwin Nolde ${ }^{15}$, Josè Pascual-Fernández ${ }^{16}$, Giuseppina Pennisi ${ }^{1}$, Bernd Pölling ${ }^{17}$, Lèlia Reynaud-Desmet ${ }^{18}$, Isabella Righini ${ }^{19}$, Youssef Rouphael ${ }^{2}$, Vèronique Saint-Ges ${ }^{20}$, Antonella Samoggia ${ }^{1}$, Shima Shaystej ${ }^{21}$, Macu da Silva ${ }^{22}$, Susana Toboso Chavero ${ }^{23}$, Pietro Tonini ${ }^{23}$, Gorazd Trušnovec ${ }^{24}$, Benjamin L. Vidmar ${ }^{25}$, Gara Villalba ${ }^{23}$ and Fabio De Menna ${ }^{1 *}$

${ }^{1}$ Department of Agricultural and Food Sciences, University of Bologna, Bologna, Italy, ${ }^{2}$ University of Naples Federico II, Naples, Italy, ${ }^{3}$ Euro-Mediterranean University, Piran, Slovenia, ${ }^{4}$ Institut für Landes- und Stadtentwicklungsforschung (ILS) - Research Institute for Regional and Urban Development, Dortmund, Germany, ${ }^{5}$ Gemeente Lansingerland, Lansigerland, Netherlands, ${ }^{6}$ Hague Corporate Affairs, The Hague, Netherlands, ${ }^{7}$ Comune di Naples, Naples, Italy, ${ }^{8}$ Comune di Bologna, Bologna, Italy, ${ }^{9}$ Metabolic Institute, Amsterdam, Netherlands, ${ }^{10}$ Flytech S.r.l., Belluno, Italy, ${ }^{11}$ Nabolagshager AS, Oslo, Norway, ${ }^{12}$ Asociatia Mai Bine, lași, Romania, ${ }^{13}$ AgroParisTech-Institut des sciences et industries du vivant et de l'environnement, Paris, France, ${ }^{14}$ Ajuntament de Sabadell, Barcelona, Spain, ${ }^{15}$ Nolde and Partner, Berlin, Germany,

${ }^{16}$ University of La Laguna, San Cristóbal de La Laguna, Spain, ${ }^{17}$ South Westphalia University of Applied Sciences, Iserlohn, Germany, ${ }^{18}$ Commune de Romainville, Romainville, France, ${ }^{19}$ Wageningen Plant Research, Wageningen University and Research, Wageningen, Netherlands, ${ }^{20}$ UMR SADAPT, INRAe, Université Paris-Saclay, AgroParisTech, Paris, France,

${ }^{21}$ Tåsen Microgreens AS, Oslo, Norway, ${ }^{22}$ Organización de Productores de Túnidos y Pesca Fresca de la Isla de Tenerife-ISLATUNA, Santa Cruz de Tenerife, Spain, ${ }^{23}$ Autonomous University of Barcelona, Barcelona, Spain, ${ }^{24}$ Urban Beekeeping Society, Ljubljana, Slovenia, ${ }^{25}$ Polar Permaculture Solutions AS, Longyearbyen, Norway

The COVID-19 pandemic unveiled the fragility of food sovereignty in cities and confirmed the close connection urban dwellers have with food. Although the pandemic was not responsible for a systemic failure, it suggested how citizens would accept and indeed support a transition toward more localized food production systems. As this attitudinal shift is aligned with the sustainability literature, this work aims to explore the tools and actions needed for a policy framework transformation that recognizes the multiple benefits of food systems, while considering local needs and circumstances. This perspective paper reviews the trends in production and consumption, and systematizes several impacts emerged across European food systems in response to the first wave of pandemic emergency, with the final aim of identifying challenges and future strategies for research and innovation toward the creation of resilient and sustainable city/region food systems. The proposal does not support a return to traditional smallscale economies that might not cope with the growing global population. It instead stands to reconstruct and upscale such connections using a "think globally act locally" mind-set, engaging local communities, and making existing and future citizen-led food system initiatives more sustainable. The work outlines a set of recommended actions for policy-makers: support innovative and localized food production, training and use of 
information and communication technology for food production and distribution; promote cross-pollination among city/region food systems; empower schools as agents of change in food provision and education about food systems; and support the development of assessment methodologies and the application of policy tools to ensure that the different sustainability dimensions of the food chain are considered.

Keywords: city/region food system, SARS-CoV-2 pandemic, sustainable food systems, food initiatives, food security

\section{INTRODUCING CITY/REGION FOOD SYSTEMS: THE FOODE VISION}

A diffuse concern about food systems' resilience has grown throughout Europe in face of the current COVID-19 crisis (Bakalis et al., 2020). Although scarcity of food was not a real threat, the crisis increased awareness on the potential exposure of food systems to new shocks and crises, especially in terms of food access (Béné, 2020), consumer behavior, small-scale productions, and alternative food networks (Galanakis, 2020). The pandemic and the related lockdown measures favored more formal and consolidated national and global supply chains, particularly in urban contexts. In fact, localized and sustainable food production and distribution experiences had to face additional challenges, such as interruptions in the supply or demand chains due to the lockdown and the need to identify new distributions channels (FAO, 2020a,b). Under these circumstances, a policy framework that takes into consideration local needs and conditions and recognizes the multiple benefits associated with localized and sustainable food production and distribution experiences (Nicholls et al., 2020) becomes more urgent than ever.

The international sustainability agenda has started to acknowledge the urgency of this shift, recommending increased diversity of plant-based foods, reduced consumption of meat, substantial cuts in food waste, and re-localization of supply chains (SCBD, 2020). Similarly, the Sustainable Development Goals Target 2 has mandated countries to ensure sustainable food production systems and double productivity and incomes of small-scale food producers (United Nations, 2015).

With reference to urban food systems, after the Global call for action conference of the World Urban Forum (2014), the City/Region Food System (CRFS) approach started to gain increasing attention within the international debate. At that time, stakeholders were already aware that a territorial and holistic food system approach was the most suitable way to tackle the upcoming global challenges.

Afterwards, the CRFS framework was introduced by Jennings et al. (2015) and defined as: "the complex network of actors, processes, relationships that has to do with food production, processing marketing, and consumption in a given geographical region which includes a more or less concentrated urban center and its surrounding peri-urban and rural hinterland."

Other than representing a multidimensional way of action, the CRFS approach entails two significant innovations. First, it aims at creating a food governance structure that considers local circumstances, understanding that cities exist within a geography and that decisions about food should operate across the urban-rural continuum. Second, such an outlook recognizes the ecological, socio-economic, and governance linkages that characterize food systems. These different dimensions not only deserve equal attention but are also recognized as mutually reinforcing (Jennings et al., 2015).

The CRFS has then become a new lens of analysis, paving the way for a more sustainable, resilient, fair, and healthy food system worldwide (World Urban Forum, 2014), and can help today in the identification of innovative solutions to cope with the aftermaths of the COVID-19 crisis.

This paper builds on the FoodE H2020 project, which sees the collaboration of 24 partners from eight European countries and aims to engage local organizations in the design, implementation, and monitoring of environmentally, economically, and socially sustainable CRFS. The goal of this paper is to offer a systematic view of European food systems response to COVID-19, highlighting the major trends and impacts and discussing the potential policy implications related to the future of CRFS.

\section{METHODOLOGY}

The work adopted a mixed-method approach integrating a literature review with the opinion of experts and stakeholders from a wide range of organizations and European countries.

Starting from the CRFS definition, a literature review was carried out to identify the most critical food system areas affected by the COVID-19 pandemic. The literature was systematized by a mixed method of research based on scientific papers and materials coming from gray literature. Concerning the peer review literature, the high number of documents acquired and revised have been collected through SCOPUS and Web Of Science. The gray literature review was carried out through Google Scholar, expert opinions, direct interviews, as well as daily press in various languages, and blogs. Collected information was clustered into five food system areas: (1) agriculture, fisheries, and production systems; (2) innovative business models for increased resilience and sustainability; and (3) evolving technologies; (4) consumers behavior changes and adaptations; and (5) schools and education. For each area a dedicated working group was created. Working groups were composed of 4-5 experts belonging to a wide range of food stakeholders types including universities and research institutes, small and medium enterprises, non-governmental organizations, and municipalities. 
TABLE 1 | Involved participants in the stakeholder's workshop, per country, and organization.

\begin{tabular}{|c|c|c|}
\hline Country & Organization & $\begin{array}{l}\text { Number of } \\
\text { participants }\end{array}$ \\
\hline \multirow[t]{4}{*}{ Italy } & $\begin{array}{l}\text { Alma Mater Studiorum - Università di } \\
\text { Bologna }\end{array}$ & 15 \\
\hline & Comune di Bologna & 3 \\
\hline & Università degli Studi di Napoli Federico II & 3 \\
\hline & Flytech & 3 \\
\hline \multirow[t]{3}{*}{ France } & $\begin{array}{l}\text { Institut des Sciences et Industries du } \\
\text { Vivant et de l'Environnement }\end{array}$ & 1 \\
\hline & $\begin{array}{l}\text { Institut National de Recherche pour } \\
\text { l'Agriculture, l'alimentation et } \\
\text { l'environnement }\end{array}$ & 1 \\
\hline & Commune de Romainville & 2 \\
\hline \multirow[t]{3}{*}{ Germany } & Fachhochschule Südwestfalen & 2 \\
\hline & $\begin{array}{l}\text { Institut für Landes- und } \\
\text { Stadtentwicklungsforschung gGmbH }\end{array}$ & 2 \\
\hline & Nolde Erwin and Partner & 1 \\
\hline \multirow[t]{2}{*}{ Netherlands } & Hague Corporate Affairs BV & 3 \\
\hline & Stichting Wageningen Research & 2 \\
\hline \multirow[t]{2}{*}{ Norway } & $\begin{array}{l}\text { Gallis Miljø Og Kommunikasjon - } \\
\text { Nabolagshager }\end{array}$ & 1 \\
\hline & Polar Permaculture Solutions & 1 \\
\hline Romania & Asociaţia Mai Bine & 1 \\
\hline \multirow[t]{2}{*}{ Slovenia } & Arctur Računalniški Inženiring & 3 \\
\hline & Društvo Urbani Cebelar & 1 \\
\hline \multirow[t]{3}{*}{ Spain } & Universitat Autònoma de Barcelona & 5 \\
\hline & Universidad de La Laguna & 1 \\
\hline & Total participants & 52 \\
\hline
\end{tabular}

The work was organized in three rounds. In the first round each working group collaborated independently to gather data, summarize relevant information, and discuss ongoing trends. The second round was represented by a large workshop engaging a wider number of stakeholders (Table 1) providing feedbacks and opinions on each of the five areas. The third round consisted in an iterative consultation process within the five working groups with the aim to integrate and review expert inputs. The joint revision enabled the systematization of the process and the harmonization of all provided contents. To follow a food supply chain logic the five groups were then reduced to three: (1) food production, covering agriculture, fisheries, and production systems, (2) food distribution, covering innovative business models for increased resilience and sustainability and evolving technologies, (3) food consumption, covering consumers behavior changes and adaptations and schools and education (EP, 2020) (Figure 1).

\section{FOOD TRENDS RELATED TO THE COVID-19 CRISIS}

The first wave of the COVID-19 outbreak did not lead to a major disruption of the European food systems, but it shed light on some specific challenges for each segment of the food chain, revealing footprints of a shift citizens might wish to embrace. The subsequent sections outline and discuss the main observed effects in food production, distribution, and consumption stages.

\section{Food Production}

Production suffered from a consistent limitation of transport lines and a generalized closing of borders. Suddenly, during the spring season, workers were unable to reach their farms, making it harder to carry out the harvest, catch and management of seasonal products. Simultaneously, the compulsory social distancing and personal protective equipment hampered the daily work in the fields. Safety measures created difficulties in production at all stages, especially for those informal chains where health and safety conditions were already limited. In these cases, implementing such measures proved challenging and led to either increased likelihood of infection or reduced production.

To buffer the labor shortage burdens, a variety of public and private actors developed apps and online platforms to match farmers' demands of seasonal staff and support mitigating production activities logistical disruptions (Laborde et al., 2020; Mitaritonna and Ragot, 2020). Despite having a consistent success, these services could not fully offset the problem, and food losses remained a major tangible concern (IOM., 2020). Other than the challenges in the fields, the stocking of products which could not reach the market at the pre-COVID19 rate, became a central issue. Only those commercial facilities having extensive capacity and enough flexibility, were able to transform products through canning or freezing techniques, while many others were left with unsold fresh products in the warehouses.

Finally, the shutdown of the Hotellerie-Restaurant-Café services, which represent a crucial market for many farmers and small producers, worsened the difficulties, reducing the sales volumes of many.

\section{Food Distribution}

The shift toward online shopping and takeaway consumption, both for fresh ingredients and ready to eat meals, led to a structural transformation of small and medium food initiatives, deeply modifying the customer relationship and sales channels. For many CRFS, whose major value proposition consists of the relational connections delivered inside and outside their organizations, the effects of social distancing measures were perceived as more severe than those experienced among more traditional food suppliers (Pulighe and Lupia, 2020). Only, in some cases, both newcomers and experienced online platforms developed communication tools that allowed maintaining such relational dimension.

Workers, but also volunteers, struggled to reach their food initiatives, creating also in this case a labor shortage (especially for food delivery) that ultimately resulted in a consistent gap within the food chain operational structure. Similarly, the logistic disruption led to inputs shortages (OECD, 2020), which made it harder to proceed with the business as usual especially for the initiatives with lower bargaining power (FAO, 2020a).

The shutdown of food and farmers' markets, together with restaurants and school canteens, contributed to the failure of 


\section{METHODOLOGY}

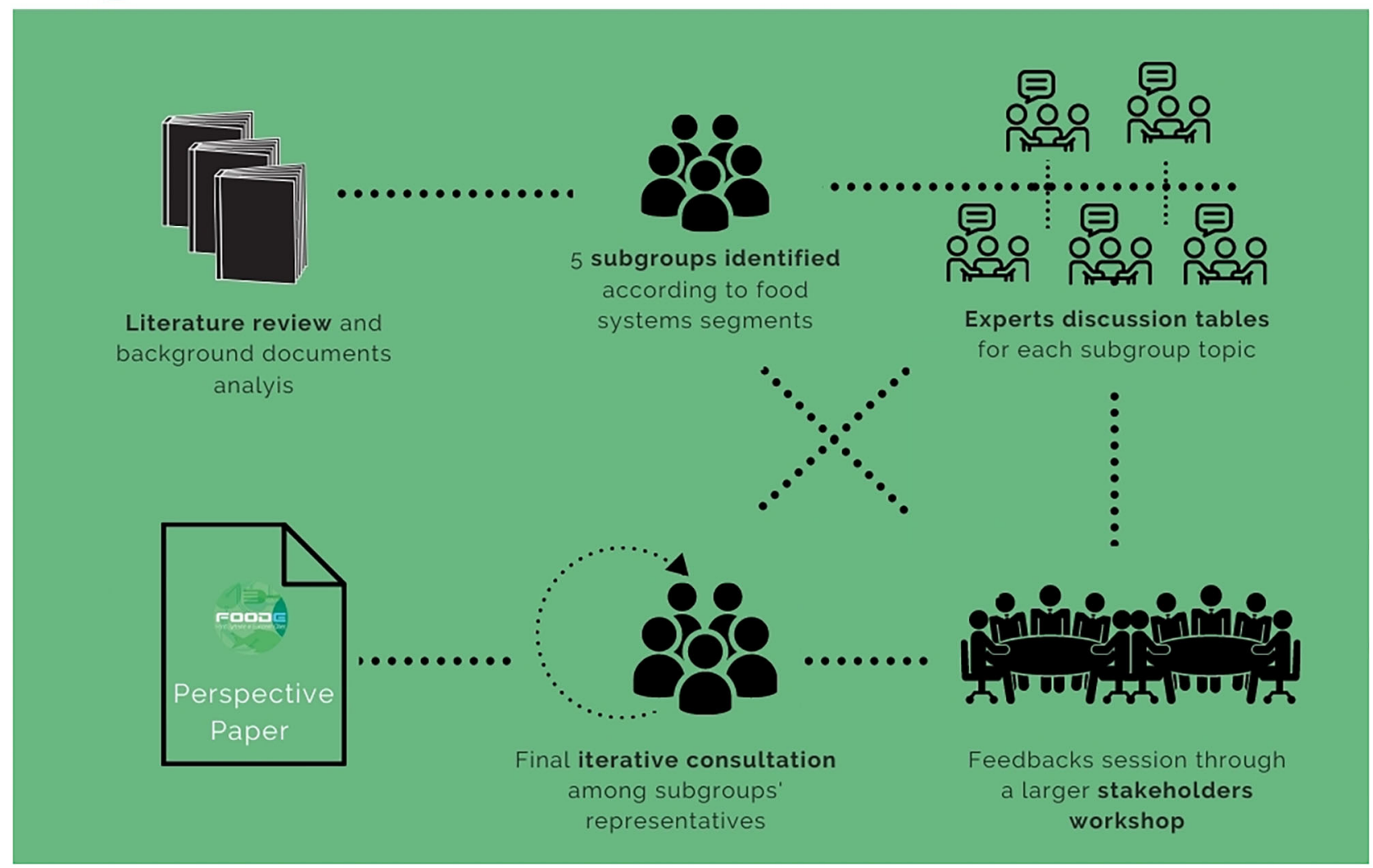

FIGURE 1 | Perspective paper methodological development.

local offer and alternative food networks. Only consolidated distribution hubs, such as supermarkets and conveniences stores, remained open at an early stage, reducing the range of choices for food actors. In some countries, as in the case of Italy, consumers were encouraged to shop in the nearest store (Gazzetta Ufficiale della Repubblica Italiana., 2020).

Large retailers were less endangered than specialist and niche shops, which were often obliged to rely on local governmental support to overcome structural and technological barriers (FAO, 2020c).

The closure of the Hotellerie-Restaurant-Café sector also had additional implications. The sector usually purchases products with different packaging as compared with home consumers. Thus, part of the packaged products was no longer marketable, leading to increased food waste (Petetin, 2020).

\section{Food Consumption}

The consumer trends that have emerged during the COVID-19 pandemic represent a major signal of change. From a household perspective, a typical consumer was motivated to maintain his or her physical and mental health and had more time available, while being more cost-conscious due to the uncertain economic situation (Accenture, 2020). As a result, consumers often adopted a back-to-basics approach to nutrition, with more home cooking and baking (Bernstein, 2020; Nielsen, 2020; OCU, 2020). Notably, citizens also stockpiled non-perishable goods, such as canned food, tomato sauce, pasta, flour, and yeast (OCU, 2020; Rogers, 2020).

Meanwhile, an increased sensitivity toward food sustainability, healthier diets, and an effort to establish stronger bonds with the origin of food emerged (Cohen, 2020; Rodríguez-Pérez et al., 2020). As an example, higher attention was given to ingredients selection, recipes scouting, and online cooking classes.

A surge in demand for short-supply chains and home delivery options, often supported by digital solutions, was observed in many countries (Hobbs, 2020). Local small-scale suppliers received larger attention by consumers since they were associated with higher safety standards and better food quality (Rizou et al., 2020). In some cases, the consumers' demand on online delivery channels consistently far exceeded the available distribution capacities (Hobbs, 2020; Nielsen, 2020). 
With regards to food waste, the preliminary evidence provided by large national surveys (Roberts and Downing, 2020; Waste Watcher, 2020) confirmed a reduction of household food waste thanks to more time for in-home food management and cooking and a better planning for grocery shopping.

Despite observing several positive trends, vulnerable groups faced severe barriers in food consumption during the lockdown. Primarily, the shutdown of school canteens affected food security and habits for entire families. According to the United Nations, World Food Programme (2020), about 320 million children saw their schools temporarily closing due to COVID-19.

Pre-COVID-19 policies in European school canteens enabled to offer high-quality food, with relevant positive effects on pupils' dietary intake (Clinton-McHarg et al., 2018; Micha et al., 2018). Consequently, the lockdown measures likely put poorer children under nutritional stress, since the school meal might represent their only adequate food intake (Dunn et al., 2020). This effect was further aggravated by the difficulties of food banks, which experienced a drop in financial resources and a shortage of volunteers (FEBA, 2020).

\section{Impacts on Food System}

Due to the exogenous nature of this shock, the COVID19 provoked a series of new behavioral shifts. Changes were quite unpredictable, leading to layered environmental, economic, governmental, and social impacts. As analyzed, observed adjustments immediately shaped consumption and production habits leading to new supply chain patterns. Depending on the governmental attitudes and capabilities, some of the rapidly emerging trends along the entire supply chain are probably destined to have a temporary nature. Others are likely to have longer-term implications.

Thanks to specific policy interventions detrimental reactions that have not shown to improve European food systems, should succeed in remaining short-term and limited to the emergency period, while beneficial shifts should be framed to guarantee their long-term viability. The results from such an uncertain and challenging period will depend on the diffused ability to correctly manage these positive and negative impacts cycles as described in Figure 2. The extent to which these mutual cycles will be reiterated will determine whether more resilient and sustainable food systems will emerge from the COVID-19 crisis.

\section{Short-Term Impacts}

Short-term impacts emerged clearly. For instance, the negative impact of social distancing measures that prevented the Hotellerie-Restaurant-Café service from using table service for their customers, has led the increasing home delivery options as a possible solution for restaurants (Laguna et al., 2020). However, this trend is likely to disappear once the emergency period will end. However, the effect might depend on the time extension of these measures, as reduced capacity would not be economically viable for an extended period (Dube et al., 2020).

In general, the relational dimension of CRFS limited by the crisis will likely be re-established or re-designed over time, creating new interactive formats, and making it easier for all actors to start working back on what CRFS initiatives consider as their core value proposition.

Similarly, the home cooking trends, connecting more deeply consumers and producers, will probably change once workers will start getting back to their regular work shifts and workplaces (Fernández-Aranda et al., 2020). Despite not leading to a longlasting positive modification of consumers eating habits, the pandemic cooking pattern might influence the food consumption vision for quite some time. Time availability and more simple food planning and management (e.g., in most of the cases all the meals were consumed at home by all the members of the family) represented key drivers in reducing food waste. However, although some of the new skills and habits might remain, the return to the pre-COVID-19 working schedule and lifestyle will probably limit the progresses obtained during the lockdown.

In certain countries, the effects of COVID-19 on household income and food security have been dramatic and were extended to a rather large share of families (Power et al., 2020; The Food Foundation, 2020). This was worsened by the changes in children's consumption patterns whose social programs and school canteens were suspended. Parents with lower awareness of healthy diets and less disposable time for cooking might have offered a less virtuous alternative to school canteens, both by reducing the attention to their children's food care and by offering them more packaged and ready-to-eat products. This phenomenon did not only affect children's diets but might have contributed to higher consumption of foods featuring larger environmental impacts and lower nutritional values.

Similarly, in some cases, new consumption behaviors also produced further unintended environmental consequences, depending on the type and amount of food purchased, as well as the related packaging. The diffusion of food delivery and last-mile emergency logistics might have resulted in increased pollution, even though partially outpaced by lockdown traffic reduction. Additionally all delivered food, required great amounts of packaging materials, whose sustainable alternatives were often too expensive to be adopted by small-scale activities.

As anticipated, according to individual priorities, these immediate changes might be converted into long-term behavioral trends, positively affecting people's daily lives. Somewhat consciously, people changed the perception of the food systems, possibly giving higher importance to local networks and adapting their shopping preferences to a new level of awareness (Béné, 2020). Growing demand for environmentally and socially ethical products has gone hand in hand with higher awareness, and these jointly will boost local food production and consumption (Hobbs, 2020). If such an intention were properly sustained, the diffusion of proximity production and distribution systems such as urban gardening and local scale farming may encourage the implementation of shorter food chains.

\section{Long-Term Impacts}

Considering long-term implications, lockdown trends also showed an increase in the online demand for foods and beverages. Once consumers have sunk the learning costs required 


\section{ENVISIONING THE FUTURE OF EUROPEAN FOOD SYSTEMS}

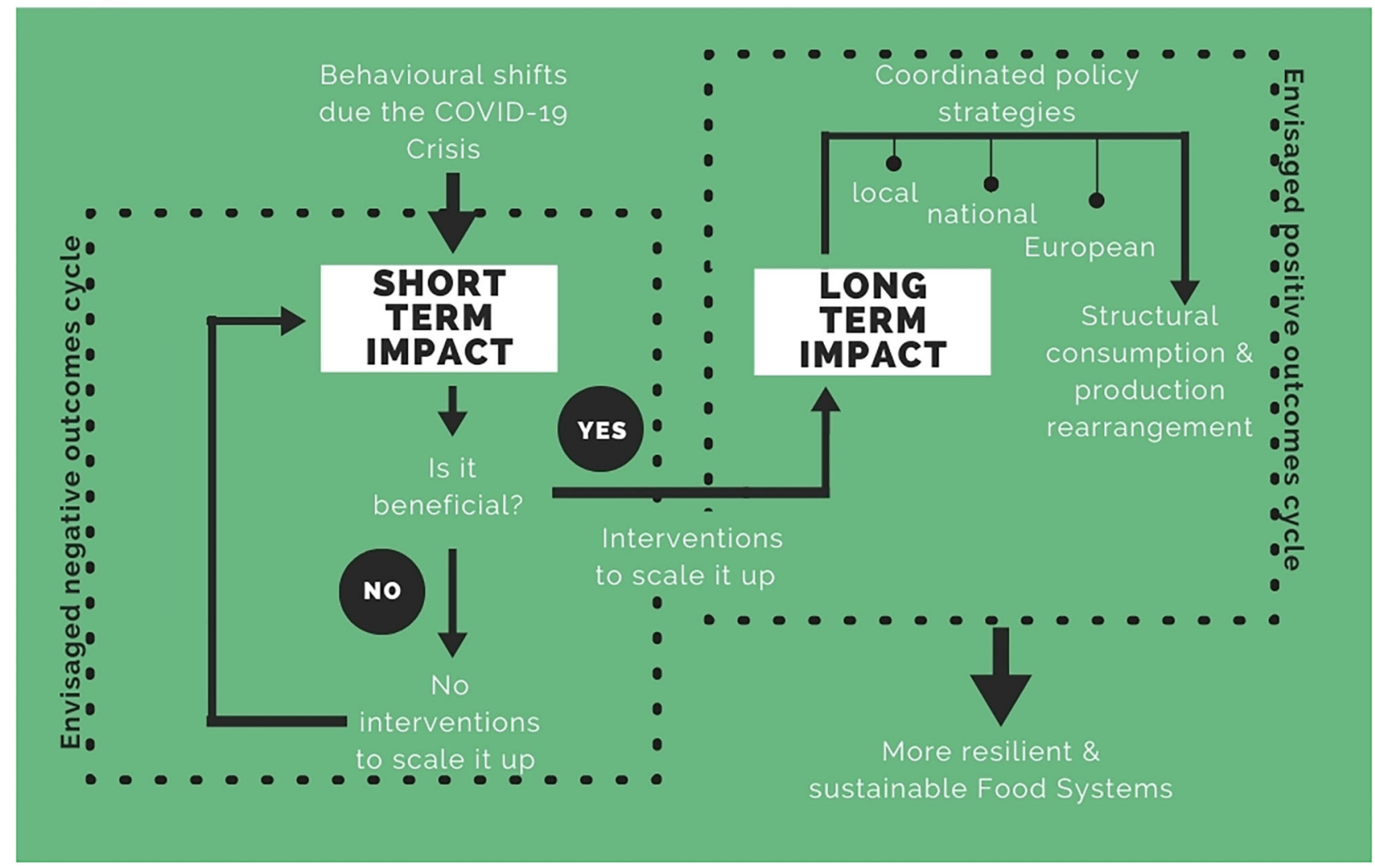

FIGURE 2 | Impacts on the European CRFS - Envisaged negative and positive outcomes cycles.

to adopt these types of food delivery and firms have adapted their spaces and operations to these shifts, changes are likely to persist well beyond the COVID-19, even though to a reduced extent.

If these digital accelerations can be seen as a virtuous innovation phenomenon for the whole sector, such a rapid transition may risk excluding smaller CRFS, ensuring major benefits only for more consolidated structures (Belavina et al., 2017; Arnalte-Mur et al., 2020). Moreover, smallholders may already face larger difficulties in recovering from the economic effects of the crisis, due to their lower business capacity.

The pandemic helped food stakeholders understanding the importance of strategic and local partnerships, both to increase their value and improve their ability to cope with possible future crises. If correctly handled, this might entail a higher number of cooperative initiatives, open innovation ecosystems, and shared networks.

Given the increased time children spent at home and the largest number of meals shared with the family, the lockdown period could have raised parent's awareness on the importance of the daily meal, giving them more time to understand children food habits, preferences, and food attitudes. Once school catering started to re-open, such dedication might end up in an increased parents' involvement in food education activities and in the design of school food quality, in terms of both food types and producers' selections. Food supply might be rethought, taking advice on the economic impact its management has on local farmers.

\section{POLICY-IMPLICATIONS: TOWARD THE FOOD SYSTEM WE WANT AND NEED}

The COVID-19 outbreak and the related responses allow to understand and evaluate the kind of possible and, indeed, desirable reforms, from a systemic point of view. In many aspects, bottom-up actions by producers and participatory consumer proposals prove to be in line with the emerging European policy agenda (EC, 2020), which indicates the commitment to address food systems imbalances. 
To reinforce this perspective and improve resilience in food supply chains local, national, and European governments should consider to:

- Encourage a diversification in food provision, including local food production, as a mean for a more resilient supply chain, promoting more substantial and innovative smallscale production systems, whose social contribution has been highlighted by the pandemic. The strategy might include actions aimed at promoting the existence of local CRFS, favoring investments into marketing and information and communication technology use for those activities that are lagging through. Examples include ad-hoc training, call for actions, and public competition opportunities. In the long run, this could help accelerate CRFS and improve competitiveness with respect to more consolidated channels.

- Promote open discussion tables and forums, partnerships, and reciprocal learning to ensure crosspollination and best practices exchange among CRFS. Besides facilitating reciprocal supports, this will help increasing the bargaining power of CRFS initiatives, making them more equipped against future time of crisis.

- Address schools as a central re-starting point. Involving teachers, families, and students in the definition of sustainable diet patterns, promoting food educational campaigns, and responsible shopping choices can help to transform cheerful consumer's behavioral change into systemic and long-lasting habits. To this scope, the provision of food in schools should put those principles in effect and should be combined with educational approaches on the community and territorial services. Similarly, open-air educational projects as urban or school vegetable gardens (Pennisi et al., 2020) can represent promising alternatives.

- Ensure that the development of policy tools include evaluations on different sustainability dimensions of the food chain. Given the evidence of the multifaceted benefits delivered by food initiatives, it is crucial to make sure all food values and attributes are considered when making decisions.

\section{CONCLUSIONS}

The first wave of the COVID-19 outbreak emphasized the need to establish new governance mechanisms engaging public authorities, citizens, small and medium enterprises, and nonprofit organizations in the conceptualization and design of new models for sustainable CRFS that deliver environmental, societal, and economic benefits. The second wave of the outbreak and the related lockdown measures will offer the chance to assess whether previous adaptations resurfaced (in case of short-term) or continued (in case of long-term) and whether policies put in place to scale up beneficial transitions were successful.
Further research commitment and stakeholders' involvement should aim at unveiling the most urgent questions, offering reasonable ground to drive the envisaged food planning.

How new systemic organizational structure and policy frameworks transforming the positive shifts into more permanent and sustainable behaviors can be created? Which type of measurements are needed to support a more holistic and integrated view on food production, distribution, and consumption to ensure equal importance at economic, societal, and environmental needs? What should be the role of government in this transition? The ability to make city/regions more resilient will crucially depend on policy stakeholders' commitment to prioritize these challenges in the local and global sustainability agenda.

\section{DATA AVAILABILITY STATEMENT}

The original contributions generated for the study are included in the article/supplementary material, further inquiries can be directed to the corresponding author/s.

\section{AUTHOR CONTRIBUTIONS}

MV, GB, SB, FC, AM, FO, JP, MP, KS, and FD equally contributed to the concept of the study, its framework, the coordination and activities of subgroups, and writing of the manuscript. SA, A-MA, TB, IB, ACo, ACr, ACu, RF-K, AG, AL, PM, EN, JP-F, GP, BP, LR-D, IR, YR, VS-G, AS, SS, MdS, ST, PT, GT, BV, and GV equally contributed to the activities of subgroups and the review of the manuscript. All authors contributed to the article and approved the submitted version.

\section{FUNDING}

The research leading to this publication has received funding from the European Union's Horizon 2020 research and innovation programme under grant agreement no. 862663. The publication reflects the author's views. The Research Executive Agency (REA) is not liable for any use that may be made of the information contained therein. This work was also supported by and ERC Consolidator grant awarded to Gara Villalba (818002-URBAG).

\section{ACKNOWLEDGMENTS}

The authors would like to thank the following contributors for their valuable inputs and feedbacks: Ilaria Braschi, Margherita Del Prete, and Francesca Monticone from the University of Bologna; Chiara Cirillo from the University of Naples Federico II; Luuk Graamans from Wageningen University and Research. The authors thank all partners in the FoodE consortium for their collaboration. 


\section{REFERENCES}

Accenture. (2020). How COVID-19 Will Permanently Change Consumer Behaviour. Fast-changing consumer behaviours influence the future of the CPG industry. Available online at: https://www.accenture.com/_acnmedia/ PDF-123/Accenture-COVID19-Pulse-Survey-Research-PoV.pdf

Arnalte-Mur, L., Ortiz-Miranda, D., Cerrada-Serra, P., Martinez-Gómez, V., Moreno-Pérez, O., Barbub, R., et al. (2020). The drivers of change for the contribution of small farms to regional food security in Europe. Global Food Security 26:100395. doi: 10.1016/j.gfs.2020.1 00395

Bakalis, S., Valdramidis, V. P., Argyropoulos, D., Ahrné, L., Chen, J., Cullen, P. J., et al. (2020). How COVID-19 changed our food systems and food security paradigms. Curr. Res. Food Sci. 3, 166-172. doi: 10.1016/j.crfs.2020. 05.003

Belavina, E., Girotra, K., and Kabra, A. (2017). Online grocery retail: Revenue models and environmental impact. Manag. Sci. 63, 1781-1799. doi: $10.1287 / \mathrm{mnsc} .2016 .2430$

Béné, C. (2020). Resilience of local food systems and links to food securityA review of some important concepts in the context of COVID-19 and other shocks. Food Security 12, 805-822. doi: 10.1007/s12571-020-0 1076-1

Bernstein. (2020). From Scratch Cooking to Home Baking: What CoronavirusFueled Trends Could Linger Post-Pandemic? Available online at: https://www. foodnavigator-usa.com/Article/2020/04/13/From-scratch-cooking-to-homebaking-What-coronavirus-fueled-trends-could-linger-post-pandemic\#

Clinton-McHarg, T., Janssen, L., Delaney, T., Reilly, K., Regan, T., Nathan, N., et al. (2018). Availability of food and beverage items on school canteen menus and association with items purchased by children of primaryschool age. Public Health Nutr. 21, 2907-2914. doi: 10.1017/S13689800180 01726

Cohen, M. J. (2020). Does the COVID-19 outbreak mark the onset of a sustainable consumption transition? Sustain. Sci. Pract. Policy 16, 1-3. doi: $10.1080 / 15487733.2020 .1740472$

Dube, K., Nhamo, G., and Chikodzi, D. (2020). COVID-19 cripples global restaurant and hospitality industry. Current Issues Tourism. doi: 10.1080/13683500.2020.1773416. [Epub ahead of print].

Dunn, C. G., Kenney, E., Fleischhacker, S. E., and Bleich, S. N. (2020). Feeding low-income children during the COVID19 pandemic. $N$ Engl $J$ Med. 382, e40. doi: 10.1056/NEJMp20 05638

EC (2020). CORONAVIRUS: Emergency Response to Support the Agriculture and Food Sectors. European Commission. Available online at: https://ec.europa.eu/ info/food-farming-fisheries/farming/coronavirus-response_en

EP (2020). European Union Food System. European Parliament. Available online at: https://www.europarl.europa.eu/RegData/etudes/BRIE/2020/652058/ EPRS_BRI(2020)652058_EN.pdf

FAO (2020a). COVID-19 and Smallholder Producers' Access to Markets. Rome.

FAO (2020b). COVID-19 crisis and support for agrifood: Public sector responses through the financial sector. Rome. Available online at: http://www.fao.org/3/ ca9846en/CA9846EN.pdf

FAO (2020c). Urban Food Systems and COVID-19: The Role of Cities and Local Governments in Responding to the Emergency. 1-6. Available online at: http:// www.fao.org/documents/card/en/c/ca8600en

FEBA (2020). European Food Banks in a post COVID-19 Europe. Available online at: https://lp.eurofoodbank.org/wpcontent/uploads/2020/07/FEBA_Report_ Survey_COVID_July2020.pdf

Fernández-Aranda, F., Casas, M., Claes, L., Bryan, D. C., Favaro, A., Granero, R., et al. (2020). COVID-19 and implications for eating disorders. Eur Eating Disord Rev. 28, 239. doi: 10.1002/e rv. 2738

Galanakis, C. M. (2020). The food systems in the era of the coronavirus (COVID19) pandemic crisis. Foods $9: 523$. doi: 10.3390/foods 9040523

Gazzetta Ufficiale della Repubblica Italiana (2020). Decreto-Legge (D.L). n.19, Misure Urgenti per Fronteggiare L'emergenza Epidemiologica da COVID-19.

Hobbs, J. E. (2020). Food supply chains during the COVID-19 pandemic. Can. J. Agric. Econ. 68, 171-176. doi: 10.1111/cjag.12237
IOM (2020). Migrants and Global Food Supply, COVID-19 Analytical Snapshot. International Organization for Migration.

Jennings, S., Cottee, J., Curtis, T., and Miller, S. (2015). Food in an Urbanised World: The Role of City Region Food Systems in Resilience and Sustainable Development. The International Sustainability Unit.

Laborde, D., Martin, W., Swinnen, J., and Vos, R. (2020). COVID-19 risks to global food security. Science 369, 500-502. doi: 10.1126/science.ab c4765

Laguna, L., Fiszman, S., Puerta, P., Chaya, C., and Tárrega, A. (2020). The impact of COVID-19 lockdown on food priorities. Results from a preliminary study using social media and an online survey with Spanish consumers. Food Qual Preference. 86:104028. doi: 10.1016/j.foodqual.2020.104028

Micha, R., Karageorgou, D., Bakogianni, I., Trichia, E., Whitsel, L. P., Story, M., Penalvo, J. L., and Mozaffarian, D. (2018). Effectiveness of school food environment policies on children's dietary behaviors: a systematic review and meta-analysis. PLoS One 13:e0194555. doi: 10.1371/journal.pone.0194555

Mitaritonna, C., and Ragot, L. (2020). After COVID-19, will Seasonal Migrant Agricultural Workers in Europe be Replaced By Robots. CEPII Policy Brief 2020-33, CEPII research center.

Nicholls, E., Ely, A., Birkin, L., Basu, P., and Goulson, D. (2020). The contribution of small-scale food production in urban areas to the sustainable development goals: a review and case study. Sustain. Sci. 15, 1585-1599. doi: $10.1007 / \mathrm{s} 11625-020-00792-\mathrm{z}$

Nielsen (2020). Coronavirus: la spesa nella GDO rispecchia le nuove abitudini domestiche. Disponibile su. Available online at: https://www.brand-news. it/intelligence/ricerche/nielsen-la-spesa-nella-gdo-rispecchia-le-nuoveabitudini-domestiche-imposte-dallemergenza-sanitaria/

OCU (2020). Organization of Consumers and Users. Available online at: https:// www.ocu.org/consumo-familia/derechos-consumidor/noticias/encuestahabitos-coronavirus

OECD (2020). Food Supply Chains and COVID-19: Impacts and Policy Lessons. 1-11.

Pennisi, G., Magrefi, F., Michelon, N., Bazzocchi, G., Maia, L., Orsini, F., et al. (2020). Promoting education and training in urban agriculture building on international projects at the Research Centre on Urban Environment for Agriculture and Biodiversity. Acta Horticult. 1279, 45-52. doi: 10.17660/ActaHortic.2020.1279.7

Petetin, L. (2020). The COVID-19 crisis: an opportunity to integrate food democracy into post-pandemic food systems. Eur. J. Risk Regul. 11, 326-336. doi: $10.1017 /$ err.2020.40

Power, M., Doherty, B., Pybus, K., and Pickett, K. (2020). How COVID-19 has exposed inequalities in the UK food system: the case of UK food and poverty. Emerald Open Res. 2:11. doi: 10.35241/emeraldopenres.13539.1

Pulighe, G., and Lupia, F. (2020). Food First: COVID-19 outbreak and cities lockdown a booster for a wider vision on urban agriculture. Sustainability 12:5012. doi: $10.3390 /$ su 12125012

Rizou, M., Galanakis, I. M., Aldawoud, T. M., and Galanakis, C. M. (2020). Safety of foods, food supply chain and environment within the COVID-19 pandemic. Trends Food Sci Technol. 102, 293-299. doi: 10.1016/j.tifs.2020.06.008

Roberts, M., and Downing, P. (2020). Citizens and Food during Lockdown. London. Available online at: https://wrap.org.uk/sites/files/wrap/Citizen_responses_to_ the_Covid-19_lockdown_0.pdf

Rodríguez-Pérez, C., Molina-Montes, E., Verardo, V., Artacho, R., GarcíaVillanov, B., Jesús Guerra-Hernández, E., et al. (2020). Changes in dietary behaviours during the COVID-19 outbreak confinement in the Spanish COVIDiet study. Nutrients 12:1730. doi: 10.3390/nu12061730

Rogers, K. (2020). Future Consumer Index: How COVID-19 is Changing Consumer Behaviours. Available online at: https://www.ey.com/en_gl/consumerproducts-retail/how-COVID-19-could-change-consumer-behaviour

SCBD (2020). Global Biodiversity Outlook. Montreal: Secretariat of the Convention on Biological Diversity.

The Food Foundation (2020). COVID-19: Latest Impact on food, 2020. London.

United Nations, World Food Programme (2020). The Closure of Schools Around the World Due to COVID-19 Risks having a Major Impact on the Health and Nutrition of School Children. Available online at: https://www.wfp.org/news/ world-food-programme-gears-support-children-left-without-meals-dueCOVID-19-school-closures 
United Nations. (2015). Sustainable Development Goals: 17 Goals to Transform Our World. Available online at: https://www.un.org/sustainabledevelopment/ sustainable-development-goals/

Waste Watcher (2020). Rapporto 2020 La Spesa ai Tempi di COVID-19. Bologna.

World Urban Forum (2014). "City region food systems and sustainable urbanisation: a call for global action," in Conference on City Region Food System and Sustainable Urban Development (Medellin: World Urban Forum).

Conflict of Interest: A-MA was employed by company Hague Corporate Affairs. ACo was employed by company Metabolic Institute. ACu was employed by company Nabolagshager AS. ACr was employed by the company Flytech S.r.l. AG was employed by company Asociatia Mai Bine. EN was employed by company Nolde and Partner. SS was employed by company Tåsen Microgreens AS. MdS was employed by company Organización de Productores de Túnidos y Pesca Fresca de la Isla de Tenerife-ISLATUNA. GT was employed by company Urban Beekeeping Society. BV was employed by company Polar Permaculture Solutions AS.
The remaining authors declare that the research was conducted in the absence of any commercial or financial relationships that could be construed as a potential conflict of interest.

Copyright (C) 2021 Vittuari, Bazzocchi, Blasioli, Cirone, Maggio, Orsini, Penca, Petruzzelli, Specht, Amghar, Atanasov, Bastia, Bertocchi, Coudard, Crepaldi, Curtis, Fox-Kämper, Gheorghica, Lelièvre, Muñoz, Nolde, Pascual-Fernández, Pennisi, Pölling, Reynaud-Desmet, Righini, Rouphael, Saint-Ges, Samoggia, Shaystej, da Silva, Toboso Chavero, Tonini, Trušnovec, Vidmar, Villalba and De Menna. This is an open-access article distributed under the terms of the Creative Commons Attribution License (CC BY). The use, distribution or reproduction in other forums is permitted, provided the original author(s) and the copyright owner(s) are credited and that the original publication in this journal is cited, in accordance with accepted academic practice. No use, distribution or reproduction is permitted which does not comply with these terms. 